\title{
An Automated Hydroponics System Based on Mobile Application
}

\author{
Kunyanuth Kularbphettong, Udomlux Ampant, and Nutthaphol Kongrodj
}

\begin{abstract}
Thai government is attempting to enhance agricultural productivity by launching campaign "Thailand 4.0" to educate farmers and raise incomes and improves the living standard of farmers. Thailand 4.0 " should be changed to make a major shift from traditional agriculture to modern agriculture by focusing on Smart Farming. . Hydroponics has become popular to grow plant without soil and many studies were shown that plants grown with hydroculture are high quality and consume fewer resources than traditional growing methods. The purposes of the research are to design and develop the automation controlling and monitoring plant growth hydroponics system and evaluate the effect of using this prototype. This system is able to control significant environmental factors that affect plant growth including temperature, humidity, and water. The application system is automatically mixed the selected solution to obtain the desired value and also collects information about the amount of solution mixed at the time of planting and it can be used to estimate the cost of growing vegetables and calculate the profitability of each vegetable to make the decision to grow. This study demonstrates the successful application of plants grown with hydroculture to improve in $\mathrm{pH}$ sensor stability and the system works well in the automated mode.
\end{abstract}

Index Terms-Automation control, monitoring, Internet of things, mobile application, and Hydroponics.

\section{INTRODUCTION}

Hydroponics system is a growing plant system that does not use soil but uses water with nutrients to save space planting and not contaminated with chemicals in the soil. Hydroponics has a number of innovative techniques and it is not limited to plant with water culture like nutrient film technique, deep flow technique, dynamic root floating technique and etc. Also, soilless culture can be divided into two major groups: water culture and substrate culture. It is high yielding and faster to plant than in the soil and the plant is fully high nutrient value and it also controls the quality of output.

Hydroponics has long been accepted in foreign countries and it is cultivated as a commercial product, such as the United States, Netherlands and Japan. In Thailand, it is more popular and focuses on expensive vegetables because the cost of growing plant is quite high. However, vegetables, cultivated with hydroponics system, are short term of harvest

Manuscript received January 13, 2019; revised May 19, 2019. This work was supported by Suan Sunandha Rajabhat University.

Kunyanuth Kularbphettong and Nutthaphol KongrodjSecodj are with Computer Science Program, Faculty of Science and Technology, Suan Sunandha Rajabhat University, Thailand (e-mail: kunyanuth.ku@ssru.ac.th, nutthaphol.ko@ssru.ac.th).

Udomlux Ampant is with Information System Program, College of Innovative Technology and Engineering, Dhurakij Pundit University. Thailand (e-mail: udomlux.amp@dpu.ac.th). and can often be rounded up to reduce costs.

Nowadays, agriculture has become more and more effective in sustainable development. Thailand 4.0 focuses on the economy driven to seek innovation of technology to help propel for the economy with Thailand 4.0. In addition, technology has become an important part of modern agriculture. Internet of Things is currently a novel trend of technology that connects and communicates electronic devices and tools such as computers, cell phones, cars, refrigerators, televisions and so on with each other through the Internet. In the future, consumers will be more familiar with the technology that makes it possible to control things from anywhere, such as home temperature control, turn on the lights, and order watering the plants.

Therefore, the automated hydroponics system based on mobile application and IOT was developed to facilitate the cultivation and the system can adjust and control important environmental factors that affect plant growth including temperature, humidity, and water. The organization of this paper is as follows. Section II presented some related works on IOT used in agriculture. Section III describes the research methodologies of the proposed system. The system design is elaborated in Section IV and Section V shown the experimental results. The conclusion and future work are given in Section VI.

\section{LITERATURE REVIEWS}

The research is based on academic principles as well as contributes to the researcher's ideas and this section shown the related works applied to this project. Nowadays, the Internet of Things, or IOT, is widely used in agriculture and there are much of researches that bring technology to assist in agriculture and show the results in comfort and productivity. The Gro-Pro hydroponic system controls automatically through android smart phone. It works well to operate four different sensors for growing plants [1]. The Titan Smartponics system handled through the web interface to control parameters by incorporating with IOT and sensors and the results displayed that the plants cultivated in control system grown better than the outside system [2].

Arduino Uno Microcontroller was used to implement nutritional water flow system and the result shown that the sensor can well detect and handle the water level in hydroponic tubes [3]. According to Mark Griffiths [4], a Hydroponics Control System manages and monitors the crucial nutrient requirements by using Arduino 2560 board and the system works well in overall functions including the $\mathrm{pH}, \mathrm{EC}$, air and water levels. The android based smart phone is designed to get data from sensor nodes and send to 
centralized computing synchronized with the WSN [5].

In addition, the use of IOT in animal product supply chain by integrated RFID and network database technology can effectively improve the supply chain situation [6] and IOT for Agricultural Environment Monitoring, the prototype collected the field environment information to investigate and real-time collect information to monitor the field [7]. Therefore, The Internet of Things has extremely widen the opportunity to enhance agricultural products with the use of cheap, easy-to-install sensors and an abundance of insightful data they offer [8].

The increasing demand of using IOT has intertwined in our lives and IOT software development is fast-paced and the detail of implement the purposed system will be further elaborated in the next section.

\section{RESEARCH METHODOLOGIES}

In the development of this system, related theory and the principles of system design were involved to meet the requirements of users. Research methodologies were including as follows:

\section{A. Hardware}

Arduino, started in the year 2005 in Italy, is the open source microcontroller board that is easy to access and develop a program. In this project, Arduino WeMos D1 is used to connect sensor device, WIFI and database and the Fig. 2 was shown the WeMos D1 as shown in Fig. 1 a). Developers can code a free program to connect electronic devices USB cable, websites, and run an application over the Internet.
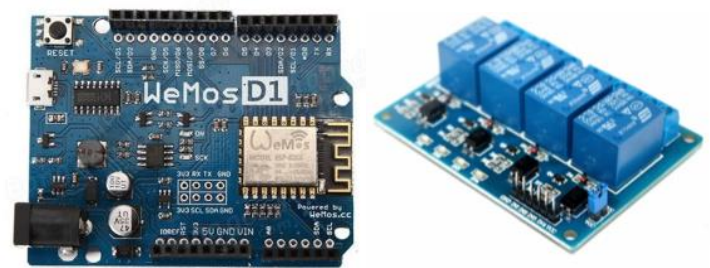

Fig. 1. a) Arduino WeMos D1, b) Relay Module.

Relay Module is the electrical switch of mains voltage to turn on or off or let the current go through or not [9] and it is used to connect with Arduino board as shown in Fig. 1 b).

Ultrasonic Sensor Module used to detect the height of water and to determine the flow of nutrition as shown in Fig. 2 a). The $\mathrm{pH}$ sensor is an electronically chemical fission device to measure the $\mathrm{pH}$ of the water by using acid-based measurement and the suitable $\mathrm{pH}$ level is between 5.5 and 7 .

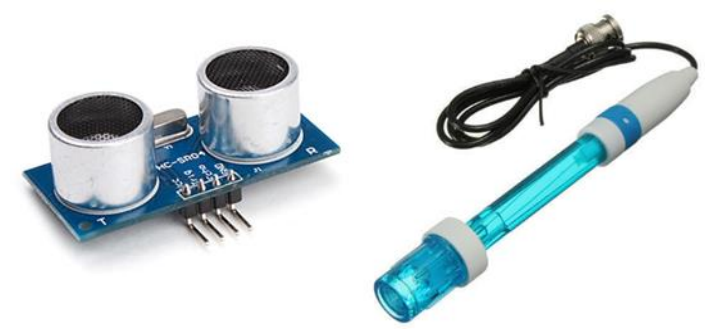

Fig. 2. a) Ultrasonic sensor module, b) the $\mathrm{pH}$ sensor.

Solenoid valve is used to keep the liquid or gas to flow until release and allow liquid or gas to pass through. Node and
MCU is an Arduino board built in Wi-Fi module and it is used to work with all sensors of the system and to send information that the sensor received into the database via Wi-Fi. MCU is the heart of IoT systems to process data and run software stacks interfaced to a wireless device for connectivity.

Ambient Light Sensor Module detects the light density and reflects the analog voltage signal back to Arduino controller.

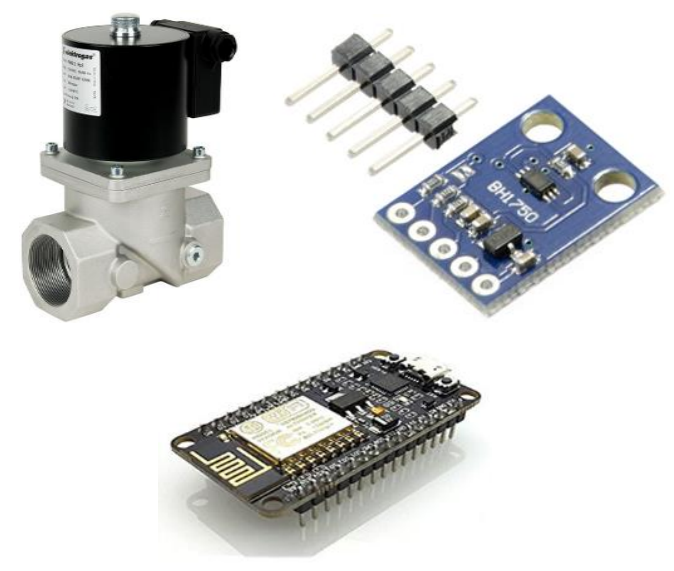

Fig. 3. a) Solenoid valve, b) Ambient light sensor, c) MCU.

\section{B. Software and Application Design}

The proposed IOT software architecture stems from satisfactory performance to support functionalities and resource heterogeneity and there are several software and application design as following this:

- Arduino IDE is an open-source application that is easy to code programs to Arduino board and it runs on Windows, Mac OS X and Linux [10]. The Arduino board is easy for connecting various accessories and lets user to connect the electronic circuit from the outside and the input and output pin of the board.

- Edge Computing is a new trend that it may be replacing the traditional cloud architecture and, unlike traditional cloud infrastructures, edge computing pushes the burden of processing data to peripheral devices in the network. This reduces the amount of information required to be sent from Edge to the cloud.

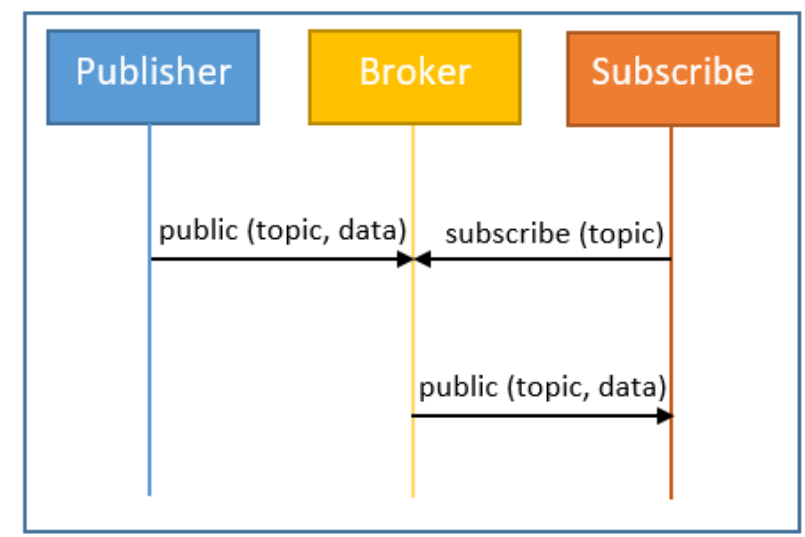

Fig. 4. Message queuing telemetry transport (MQTT).

- Message Queuing Telemetry Transport (MQTT) is lightweight messaging protocol for M2M communication with remote locations where a "small code footprint" is required or the network bandwidth is limited [11]. This protocol is designed for use with small electronics based 
on publisher/subscriber. Also, MQTT is suitable to be used with a sensor device that has a small processor on a remote network with low power consumption and very limited bandwidth. MQTT is a Client-Server architecture with hub-and-spoke topology and the destination sensor acts as a client that creates a TCP connection to a server called Broker, which is responsible for transmitting data between messages that are both Publisher and Subscriber as shown in Fig 4.

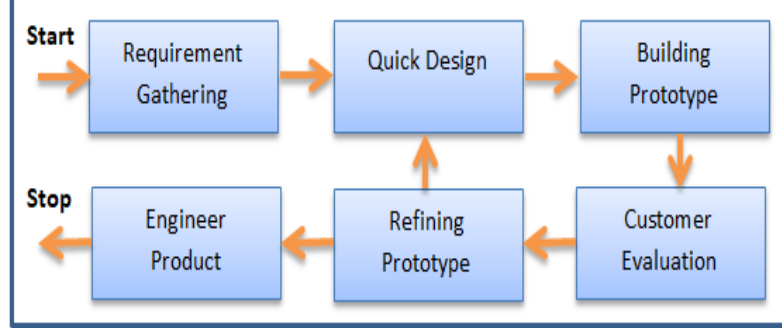

Fig. 5. The process of prototype model [12].

- Prototype model is a systems development approach to develop system by creating a prototype in order to allow users to shape the system and to clearly reduce the error occurring requirement specification process as display Fig. 5 [12].

- Firebase is designed to be API and Cloud Storage for real time Application and it supports multiple platforms, including IOS App, Android App, and Web App.

Currently, Firebase Real-time Database is a popular database service for mobile app development, web, games and IoT because the advantage is able to sync data for all clients in real time, to store data as a NoSQL JSON. Moreover, it has the structure of schema less and supports offline functionality.

\section{SYSTEM DESIGN}

This research is implemented the automated hydroponics system based on IOT and smart phone to support planting hydroponic vegetables. The system can be measured and displayed information through mobile phone to manage and control over the related sensor devices like temperature, pressure of water supply system. The system overview is displayed as Fig. 5. The experimental set is allowed on the acquisition of land by setting temperature 30-35 degrees, soil moisture 50-60 percent, and the intensity of light at $2-5$. The application will record data received from the related sensors every 10 minutes. Furthermore, the prototype gets information from the database every 1 minute and plants grown in normal conditions.

The system includes 4 sections to control and manage the automatic hydroponics application. Arduino boards are used to control the various functions of the system, including temperature and humidity sensors, light sensors, the $\mathrm{pH}$ sensor, and the water level sensor. The proposed system covers the process from sending data measured sensor devices, receiving data from an intermediary data storage and sending data to the host computer. Then, the system will analyze the sent value and relay module acts as a switch to turn on-turn off the related module.

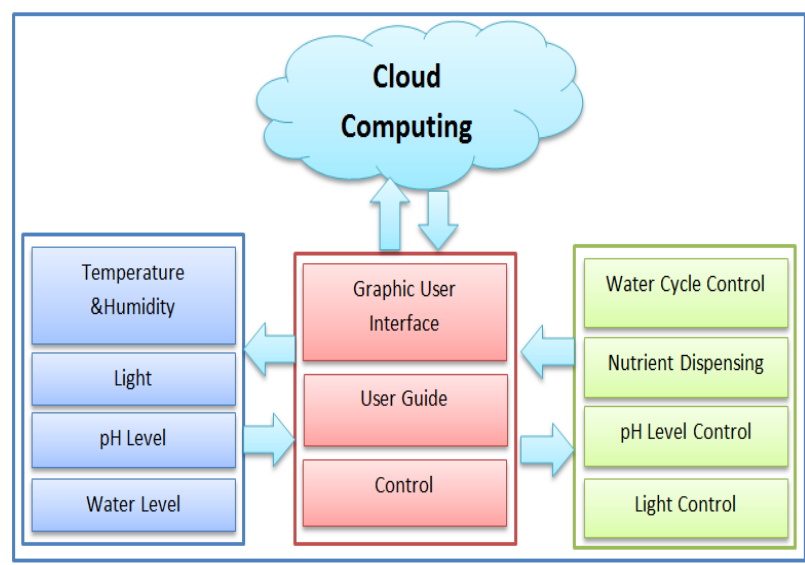

Fig. 6. System overview.

Section 1: to control the discharge of water, when system gets the value from the temperature and humidity sensors, the spayed water will be released in case of the temperature higher than the indicated value.

Section 2: to control light level, the turn on - turn off the LED from the board received the value from the light sensor and when the intensity of light is lower than the set value, the system will operate relay module to turn on the LED until the intensity is equal or greater than the set value.

Section 3: the $\mathrm{pH}$ control is started when the $\mathrm{pH}$ value is higher than the set value and the system will release the $\mathrm{pH}$ solution until the $\mathrm{pH}$ value is lower than the set value.

Section 4: to control the water level, the water level sensor will notify the vale to the system and when the water level is lower than the indicated value, the application will release water into the vegetable plot until the water level is equal or higher a set value. The system gets the sensor data and records every hour, collected from 07.00 to 18.00 . Also, the prototype can access and control through both mobile and web based application.

\section{EXPERIMENTAL RESULTS}

The results of this research are divided by the research objectives into 2 parts: testing the automated hydroponics vegetable system and evaluating user's satisfaction of this prototype.

\section{A. Testing the Automated Hydroponics Vegetable System}

In the experiment, to evaluate and test the proposed project used, all devices that are based on the standard Message Queuing Telemetry Transport (MQTT) and each device sent the data into the system, including the receiving data (subscribe). we compared the three parts including: the light value, the quality of the product and the level of water and when compared with the light value, vegetables grown in the control system with orange light (20000-40000 lux) are better growing than the vegetables grown with regular approach. Also, the result was shown that the amount plant grown in greenhouse with harvest was $35 \%$ and the growth plants were $15 \%$. Germination from seed was rate at $20 \%$ and the seeds do not grow at $65 \%$. While the sampling of seeds was grown in normal conditions, the number of plants grown was at $18 \%$ and the growth plants were $10 \%$. Germination from seed was rate at $25 \%$ and the seeds do not grow at $67 \%$. In addition, 
salad vegetables in the control system take about 50 days while compared with the regular method.

\section{B. Evaluating User's Satisfaction of This Prototype}

Black-Box Testing is the software testing developed on the basis of the program or system's functionality. There are 5 aspects of satisfaction to evaluate the performance of the application as follows [13]:

1) The Functional Requirement Test is to assess the effectiveness of the system to meet the needs of the user.

2) The Functional Test is to measure how the function of system works.

3) The Usability Test is a systematic assessment of how easy to use the system.

4) The Security Test is a systematic assessment of the security of data in the system

5) The Integrity Test is a complete assessment of the integrity of the system.

TABLE I: FUNCTIONAL REQUIREMENT TEST

\begin{tabular}{|c|c|c|c|}
\hline \multirow{2}{*}{ Functional Requirement Test } & \multicolumn{3}{|c|}{ Performance } \\
\hline & $\overline{\mathbf{x}}$ & S.D. & meaning \\
\hline $\begin{array}{l}\text { 1. The Hydroponics Systems returns } \\
\text { accuracy of results }\end{array}$ & 4.75 & 0.44 & Very Good \\
\hline 2. The System can work completely & 4.6 & 0.68 & Very Good \\
\hline $\begin{array}{l}\text { 3. The system provides information } \\
\text { on Hydroponics vegetable systems } \\
\text { to easy understand. }\end{array}$ & 4.3 & 0.92 & Good \\
\hline Average & 4.55 & 0.45 & Very Good \\
\hline
\end{tabular}

TABLE II: FUNCTIONAL TEST

\begin{tabular}{|c|c|c|c|}
\hline \multirow{2}{*}{ Functional Test } & \multicolumn{3}{|c|}{ Performance } \\
\hline & $\overline{\mathbf{x}}$ & S.D. & meaning \\
\hline $\begin{array}{l}\text { 1. The correct result is scoped in the } \\
\text { boundaries set. }\end{array}$ & 4.3 & 0.80 & Good \\
\hline $\begin{array}{l}\text { 2. The system has a good } \\
\text { management system }\end{array}$ & 4.3 & 0.80 & Good \\
\hline Average & 4.30 & 0.75 & Good \\
\hline
\end{tabular}

TABLE III: USABILITY TEST

\begin{tabular}{|c|c|c|c|}
\hline \multirow{2}{*}{ Usability Test } & \multicolumn{3}{|c|}{ Performance } \\
\hline & $\overline{\mathbf{x}}$ & S.D. & meaning \\
\hline $\begin{array}{l}\text { 1. Users understand how to use the } \\
\text { system }\end{array}$ & 4.45 & 0.51 & Good \\
\hline $\begin{array}{l}\text { 2. The system shows clearly the } \\
\text { information }\end{array}$ & 4.45 & 0.69 & Good \\
\hline $\begin{array}{l}\text { 3. The system displays the suitable } \\
\text { graphical user interface. }\end{array}$ & 4.35 & 0.81 & Good \\
\hline Average & 4.41 & 0.39 & Good \\
\hline
\end{tabular}

TABLE IV: INTEGRITY TEST

\begin{tabular}{|lccc|}
\hline \multicolumn{1}{|c|}{ Integrity Test } & $\overline{\mathbf{x}}$ & S.D. & meaning \\
\hline $\begin{array}{l}\text { 1. There are all functions as defined } \\
\text { by the field }\end{array}$ & 4.25 & 0.72 & Good \\
\hline $\begin{array}{l}\text { 2. The database is used for easy } \\
\text { editing. }\end{array}$ & 4.45 & 0.69 & Good \\
\hline \multicolumn{1}{|l|}{ Average } & 4.35 & 00.46 & Good \\
\hline
\end{tabular}

The results were presented from Table I to table IV. The average of Functional Requirement Test is very good and the average of Functional Test, Usability Test, Security Test and
Integrity Test were good as shown in Fig. 7.

TABLE IV: SECURITY TEST

\begin{tabular}{|l|ccc|}
\hline \multicolumn{1}{|c|}{ Security Test } & \multicolumn{3}{c|}{ Performance } \\
\hline $\begin{array}{l}\text { 1. The suitability of the information } \\
\text { presented. }\end{array}$ & 4.1 & 0.72 & Good \\
\hline 2. The system has a system security & 3.9 & 0.85 & Good \\
\hline Average & 4 & 0.58 & Good \\
\hline
\end{tabular}

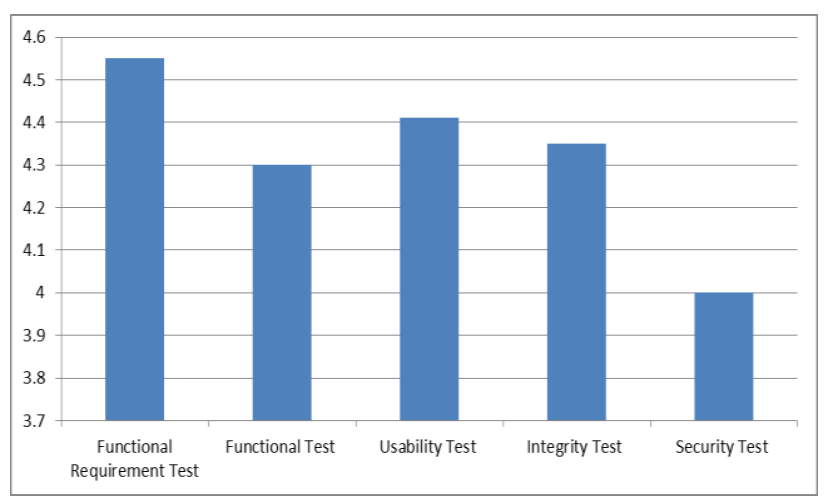

Fig. 7. The results of black box testing.

\section{CONCLUSION}

In this research, the researcher aims to make a convenience and productivity to users who need to plant hydroponic vegetable by using IOT and mobile phone to automatically control and monitor the automatic hydroponics vegetable system. The system can check and refill the nutrient by self-regulating and displays the graphic user interface to easy manage and control it. However, the system is divided into two parts: the automatic part, the manual part, which allows the user to control the measurement of light, temperature and humidity. In addition, the results that were tested with the user were satisfactory and the application is convenient and the productivity also increases obviously. For future research, the system will develop to have more useful and versatile related devices and data mining techniques will be applied to analyze and predict information about quantity, quality and time aspects.

\section{ACKNOWLEDGMENT}

We would like to thank Suan Sunandha Rajabhat University to support financial subsidy throughout this project.

\section{REFERENCES}

[1] M. D’Anna. Automated hydroponic greenhouse. [Online]. Available: www.ecs.umass.edu/ece/sdp/sdp17/team03/assets/documents/Final_R eport.pdf

[2] V. Palandea, A. Zaheera, and K. Georgea, "Fully automated hydroponic system for indoor plant growth," Procedia Computer Science, vol. 129, 2018, pp. 482-488.

[3] P. Sihombing, N. A. Karina, J. T. Tarigan, and M. I. Syarif, "Automated hydroponics nutrition plants systems using arduino uno microcontroller based on android," presented at 2nd International Conference on Computing and Applied Informatics 2017, IOP Conf. Series: Journal of Physics: Conf. Series 978, 2018, p. 012014.

[4] M. Griffiths, "The design and implementation of a hydroponics control system," Oulu University of Applied Sciences, Thesis, Autumn 2014. 
[5] S. Tembekar and A. Saxena, "Monitoring wireless sensor network using android based smart phone application," IOSR Journal of Computer Engineering (IOSR-JCE), vol. 16, issue 2, pp. 53-57, 2014

[6] M. S. H. Talpur et al., "Relevance of internet of things in animal stocks chain management in Pakistan's perspectives," International Journal of Information and Education Technology, vol. 2, no. 1, February 2012.

[7] C.-J. Zou, "Research and implementation of agricultural environment monitoring based on internet of things," presented at 2014 Fifth International Conference on Intelligent Systems Design and Engineering Applications, 15-16 June 2014

[8] P. R. Lakshmi and D. S. Mahalakshmi, "IOT based crop field monitoring and irrigation automation," presented at International Conference on International System and Control, 2016.

[9] Guide for Relay Module with Arduino. [Online]. Available: https://randomnerdtutorials.com/guide-for-relay-module-with-arduino I

[10] Arduino Web Editor. [Online]. Available: https://www.arduino.cc/en/Main/Software

[11] MQTT. [Online]. Available: https://en.wikipedia.org/wiki/MQTT

[12] D. Thakur. Prototyping model in software engineering. [Online]. Available:

http://ecomputernotes.com/software-engineering/explain-prototypingmodel

[13] K. Kularbphettong and N. Limphoemsuk, "The effective of learning by augmented reality on Android platform," LNICST, vol. 180, pp 111-118, 2017.

Copyright $(9) 2019$ by the authors. This is an open access article distributed under the Creative Commons Attribution License which permits unrestricted use, distribution, and reproduction in any medium, provided the original work is properly cited (CC BY 4.0).

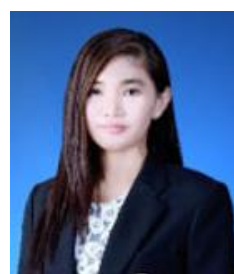

Kunyanuth Kularbphettong is assistant professor of computer science program, Faculty of Science and Technology, Suan Sunandha Rajabhat University. Thailand. She received the Ph.D in information technology from King Mongkut's University of Technology North Bangkok, Thailand. Her research interests are IOT, data mining, machine learning, software applications and educational learning.

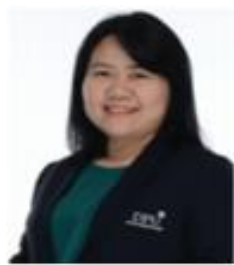

Udomlux Ampant is senior lecturer of information system program, College of Innovative Technology and Engineering, Dhurakij Pundit University. Thailand. She graduated the master of business administration (marketing) Dhurakij Pundit University. Her research interests include IoT technology machine learning and software applications. She has published more than 5 papers in the fields of machine learning, educational technology and software applications.

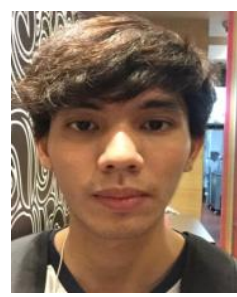

Nutthaphol Kongrodj is with computer science program, Faculty of Science and Technology, Suan Sunandha Rajabhat University. Thailand. $\mathrm{He}$ received the bachelor degree in computer science and his research interests in IOT and software applications. 